\title{
The Preference of Children and their Parents About the Pediatric Dentist's Appearance
}

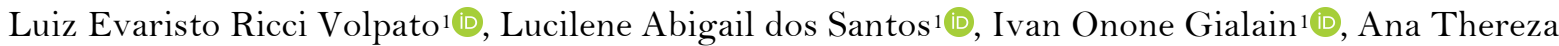
Saboia de Campos Neves ${ }^{1}$, Andreza Maria Fabio Aranha ${ }^{1}$ (D)

'School of Dentistry, University of Cuiabá, Cuiabá, MT, Brazil.

Correspondence: Luiz Evaristo Ricci Volpato, Rua Estevão de Mendonça, 317, Goiabeiras, Cuiabá, MT, Brazil. $78032-085$. E-mail: odontologiavolpato@uol.com.br

Academic Editor: Burak Buldur

Received: 28 December 2020 / Review: 09 March 2021 / Accepted: 31 March 2021

How to cite: Volpato LER, Santos LA, Gialain IO, Neves ATSC, Aranha AMF. The preference of children and their parents about the pediatric dentist's appearance. Pesqui Bras Odontopediatria Clín Integr. 2021; $21: e 0268$. https://doi.org/10.1590/pboci.2021.125

\begin{abstract}
Objective: To analyze whether children and their parents prefer a particular professional coat worn by the dentist and whether these preferences are influenced by their gender or level of anxiety. Material and Methods: Standardized images of male and female models dressed with different coats were shown to 400 pairs of 5-12 year-old children and respective parents and they were asked to point their preference. Information about child's dental experience was collected and children's anxiety level was obtained using the Children's Fear Survey Schedule-Dental Subscale. Results: Both children (55.5\%) and parents (76.5\%) preferred a female professional over a male one. Children preferred the dentist wearing a white coat, while adults preferred the dentist wearing a colored coat $(\mathrm{p}<0.05)$. There was a tendency for the child to choose a dentist with the same gender as theirs, so boys chose more male dentists and girls more female dentists $(\mathrm{p}<0.05)$, but there was no difference between the choice of the dentist's coat between boys and girls $(p=0.53)$. Conclusion: Children have strong preferences in relation to the appearance of their dentists. Children and parents preferred female dentists, but there was a tendency to choose the dentist with the respondent's gender. Contrary to popular belief, children preferred their dentists wearing the conventional white coat, different from their parents who preferred dentists wearing a colored coat.
\end{abstract}

Keywords: Dental Anxiety; Child Behavior; Oral Health; Social Perception. 


\section{Introduction}

It is fundamental for dentists to understand how behavioral management of pediatric patients should be, and to follow new techniques and changes within the contemporary development of dentistry [1]. A good communication and a dentist's appropriate behavior management can reduce children's dental anxieties and motivate them to collaborate with the treatment [2]. By gaining the child's confidence, it becomes possible to deal with the causes of anxiety and to reduce their pre-existing fears [3].

Visual impression is a determining aspect of non-verbal communication for building a good relationship between dentist and patient [3]. During the first visit to the dental office, before any verbal communication, the impression about a dentist is developed based on clothing, hygiene and cleaning [4].

Currently, there is a tendency to use colored coats when providing dental care to pediatric patients [5]. However, there is no consensus regarding this conduct [6]. Some studies did not find a significant difference between the preferences of children and their guardians in relation to the gender and the clothing worn by the dentist [4,7]. Other studies found a stronger preference for the white traditional coat $[6,8,9]$ or for colored coats [10]. It is important to note that characteristics such as the child's age group, gender, anxiety level, previous medical experience, among others, interfered in preferences [3,6,8-14].

A recent systematic review of the literature with meta-analysis analyzed the preference of children in relation to the clothing used by the dentist [5]. The authors did not find any work in this sense done with Latin American or Brazilian children, demonstrating the need of research with children from different regions to assess whether preferences and behaviors are related to cultural aspects, both in relation to the preference for the clothing worn by the dentists and their gender.

Thus, the objective of this research was to access the preference of children and their parents to the type of professional coat and gender of the pediatric dentist and to evaluate if the preference is correlated to the children's previous dental experience and anxiety level. The null hypothesis is that the children and their parents have no specific preference regarding the professional coat and gender and that the preferences are not correlated to the children's previous dental experience and anxiety level.

\section{Material and Methods}

Study Design and Ethical Clearance

Before the beginning of the data collection of this cross sectional study, this research was approved by the Research Ethics Committee, protocol \#3.088.269/2018. All children and their parents were informed about the research and, when they agreed to participate in the study, respectively signed informed assent and consent forms.

\section{Sampling}

The inclusion criteria for participation in the study were: adults and children able to understand and communicate in Portuguese and children with physical status ASA I or II [15]. The exclusion criteria were: children cognitively deficient and unable to complete the research independently; children who are not accompanied by their legal parents. Questionnaires that had missing information were also excluded from the study.

As there were no similar studies carried out in Brazil, the sample size for this study was calculated based on estimates in order to detect a minimum difference of 1.123, and assuming a standard deviation of 8 on 
the Children's Fear Survey Schedule-Dental Subscale (CFSS-DS) (0-75 range), with a power of 0.05 and $80 \%$ [12], resulting in a non-probabilistic sample of 400 pairs of children and parents.

\section{Data Collection}

Children and parents were interviewed separately in public spaces such as parish centers, squares and parks by L.A.S. The parent's questionnaire consisted of three sections, while the child's questionnaire involved only questions from Section 2.

Section 1: Demographic data and child's dental history. Demographic data included age andgender of the child and the parent. The child's dental history included questions about the first consultation (yes / no), dental procedures undergone (yes / no) and type of procedure undergone (prophylaxis and fluoride application; dental scaling; restorations; extractions and pulp treatments).

Section 2: Gender and clothing preference. A card with six photographs of male and female models dressed in three different outfits (white coat, dark blue coat and colored coat) was shown to the participants. In all the photographs, the facial expression, posture and hairstyle of the models were kept as similar as possible (Figure 1). Children and their parents were asked to independently choose how they would prefer the dentist to be. None of the individuals portrayed in the photographs were involved in the research or in possible dental assistance. The option for "no preference" was not available, ensuring that all participants would choose one of the photographs shown.
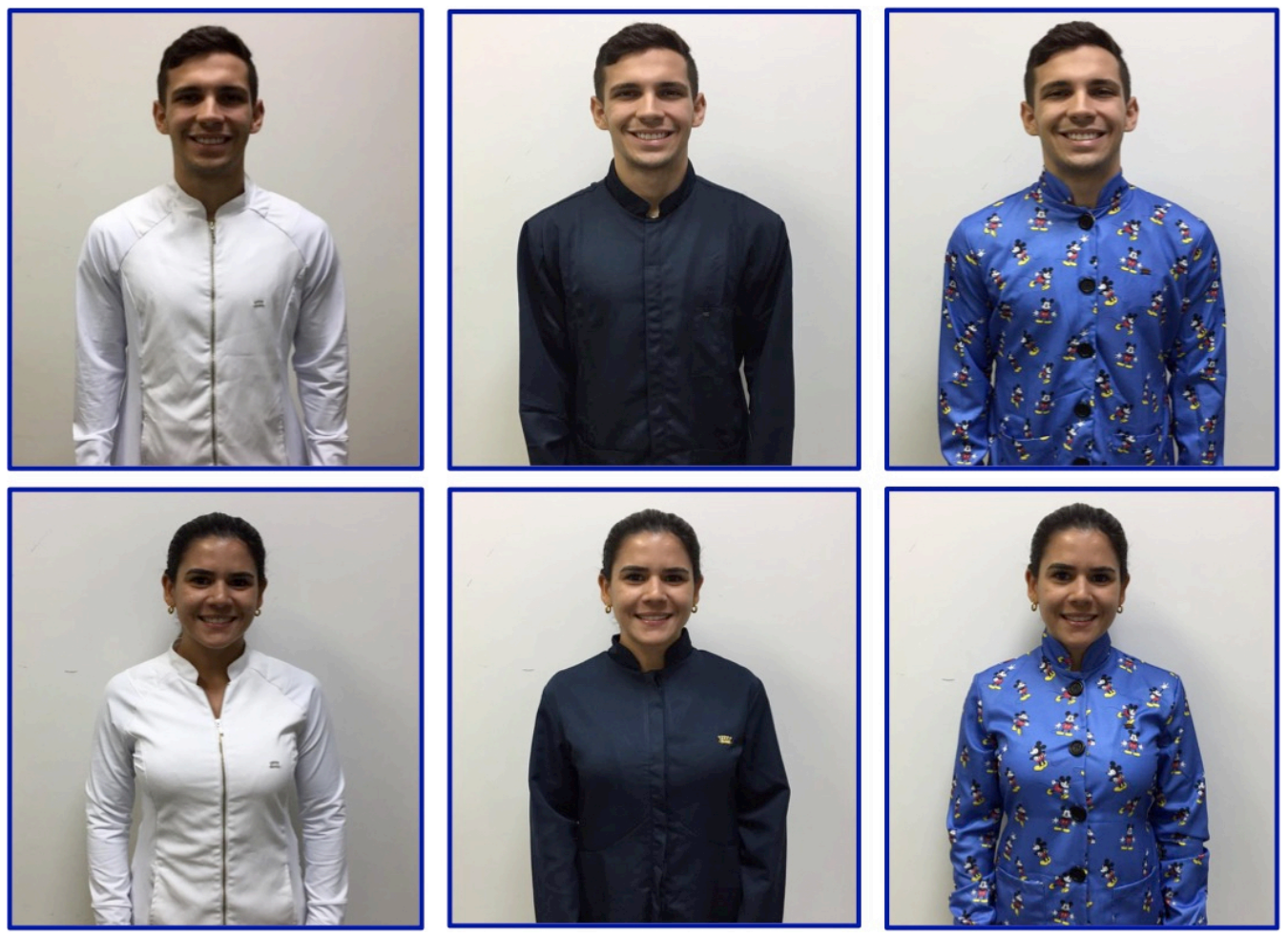

Figure 1. Card showing male and female models dressed in white coat, dark blue coat and colored coat.

Section 3: Children's Fear Survey Schedule-Dental Subscale (CFSS-DS). Parents were asked to answer a list of 15 questions to determine their child's level of anxiety. The CFSS-DS comprises different domains that contribute to dental anxiety based on a Likert scale ranging from 1 (without fear) to 5 (very afraid) [16]. The scores were added to give the CFSS-DS score (range 15-75). To facilitate comparison with existing studies, the 
score of 38 was defined as the cutoff point for dental clinical fear [17], with a score of $<38$ denoting the absence of dental anxiety, and $\geq 38$ indicating the presence of dental anxiety.

The pre-test of the questionnaire (pilot study) was conducted on 30 pairs of children and parents to ensure that the questions were adequate for the purpose, to test the ease of understanding, ambiguity and to evaluate the workflow of the data collection process. The results obtained were not included in the analysis of the data of the final study. The average time spent to fill the questionnaire was 10 minutes.

Data Analysis

The data were analyzed using the IBM SPSS Statistics for Windows program (version 22.0, IBM Corp, Armonk, NY, USA) and a significance of $\mathrm{p}<0.05$ was considered. The chi-square test was used to verify the difference in the distribution of preferences for choosing the gender of the dentist and the type of coat for the responses obtained from the children and their parents. The chi-square test was also used to verify significant associations between the variables studied.

\section{Results}

A non-probabilistic sample was obtained with 400 children and 400 parents in the study. There was a higher frequency of girls $(n=215,53.8 \%)$, as well as mothers $(n=346,86.5 \%)$. Regarding the children's age, the most frequent was 8 years old (16\%) (Table 1$)$.

Table 1. Distribution of children and parents according to age and gender.

\begin{tabular}{ccc}
\multicolumn{1}{c}{ Variables } & $\mathbf{N}$ & \% \\
\hline Children's Gender & 215 & 53.8 \\
Female & 185 & 46.3 \\
Male & & \\
Children's Age (in Years) & 42 & 10.5 \\
5 & 61 & 15.2 \\
6 & 63 & 15.8 \\
7 & 65 & 16.2 \\
8 & 42 & 10.5 \\
9 & 50 & 12.5 \\
10 & 42 & 10.5 \\
11 & 35 & 8.8 \\
12 & & \\
Parents' Gender & 346 & 86.5 \\
Female & 54 & 13.5 \\
Male & & \\
\hline
\end{tabular}

Considering the dental history of the children interviewed, $353(88.3 \%)$ had already attended a dentist and $338(84.5 \%)$ had undergone some procedure. The most common procedure were prophylaxis and fluoride application 298 (74.5\%) (Table 2 ).

Table 2. Distribution of children according to the dental history.

\begin{tabular}{lcc}
\multicolumn{1}{c}{ Dental History } & N & \% \\
\hline Previous Visit to the Dentist & 353 & 88.3 \\
$\quad$ Yes & 47 & 11.8 \\
$\quad$ No & & \\
Had Undergone Any Procedure? & 338 & 84.5 \\
$\quad$ Yes & 62 & 15.5 \\
No &
\end{tabular}




\begin{tabular}{lcc} 
Procedure Undergone & & \\
Prophylaxis and Fluoride Application & 298 & 74.5 \\
Dental Scaling & 17 & 4.3 \\
Restoration & 156 & 39.0 \\
Extraction & 97 & 24.3 \\
Pulp Treatment & 12 & 3.0 \\
Other & 33 & 8.3 \\
\hline
\end{tabular}

Both children and parents preferred the female dentist over the male dentist ( $p=0.028$ for children and $\mathrm{p}<0.001$ for parents). The children preferred the white coat, while the parents preferred the colored coat $(\mathrm{p}<0.001$ for both children and adults) (Table 3$)$.

Table 3. Distribution of preference of children and parents to the dentist's gender and type of coat.

\begin{tabular}{lcccc}
\hline \multicolumn{1}{c}{ Preference } & Child & p-value & Parent & p-value \\
& $\mathrm{N}(\%)$ & & & \\
\hline Dentist's Gender & & & & \\
$\quad$ Female & $222(55.5)$ & $0.028^{*}$ & $306(76.5)$ & $<0.001^{*}$ \\
Male & $178(44.5)$ & & $94(23.5)$ & \\
Type of Coat & & & $144(36.0)$ & $<0.001^{*}$ \\
White Coat & $178(44.5)$ & $<0.001^{*}$ & $15(3.8)$ & \\
$\quad$ Dark Blue Coat & $87(21.8)$ & & $24.1(60.3)$ & \\
Colored Coat & $135(33.8)$ & &
\end{tabular}

*Chi-square test $(\mathrm{p}<0.05)$.

There was a tendency for the child to choose the dentist with the same gender as theirs, therefore, boys chose more male dentists and girls more female dentists $(\mathrm{p}<0.001)$, however there was no difference between the choice of the dentist's coat between boys and girls $(p=0.53)$. There was no difference in the preference of the gender of the dentist or the color of the dentist's coat between fathers and mothers $(p=0.425$ and $\mathrm{p}=0.549$, respectively) (Table 4 ).

Table 4. Distribution of preference of children and parents according to gender in relation to gender and type of dentist's coat $(n=400)$.

\begin{tabular}{|c|c|c|c|c|c|c|}
\hline \multirow[b]{2}{*}{ Preference } & \multicolumn{3}{|c|}{ Child } & \multicolumn{3}{|c|}{ Parent } \\
\hline & $\begin{array}{c}\text { Boy } \\
\mathrm{N}(\%)\end{array}$ & $\begin{array}{c}\text { Girl } \\
\mathrm{N}(\%)\end{array}$ & p-value & $\begin{array}{l}\text { Father } \\
\mathrm{N}(\%)\end{array}$ & $\begin{array}{c}\text { Mother } \\
\mathrm{N}(\%)\end{array}$ & p-value \\
\hline \multicolumn{7}{|l|}{ Dentist's Gender } \\
\hline Female & $50(12.5)$ & $172(43.0)$ & $<0.001^{*}$ & $79(19.8)$ & $267(66.8)$ & 0.425 \\
\hline Male & $135(33.75)$ & $43(10.75)$ & & $15(3.8)$ & $39(9.8)$ & \\
\hline \multicolumn{7}{|l|}{ Type of Coat } \\
\hline White Coat & $79(19.8)$ & $99(24.8)$ & 0.530 & $23(5.8)$ & $121(30.3)$ & 0.549 \\
\hline Dark Blue Coat & $50(12.5)$ & $37(9.3)$ & & $2(0.5)$ & $13(3.3)$ & \\
\hline Colored Coat & $56(14.0)$ & $79(19.8)$ & & $29(7.2)$ & $212(53.0)$ & \\
\hline
\end{tabular}

There was a significant concordance between the choice of the dentist's gender by the parent with the child's preference, that is, when a child preferred a female dentist, the parent who accompanied them had also chosen a female dentist $(\mathrm{p}<0.002)$. The same concordance was not observed in relation to the dentist's type of coat $(\mathrm{p}=0.113)$ (Table 5$)$.

According to the Children's Fear Survey Schedule-Dental Subscale (CFSS-DS), it was observed that most children were not afraid of dentist $(n=240,60.0 \%)$, of choking $(n=183,45.8 \%)$ and of people wearing white clothes ( $\mathrm{n}=332,83.0 \%)$, differing only from the fear of anesthesia, which of the 400 children $179(44.8 \%)$ were very afraid of (Table 6). 
Table 5. Relationship between the choice of the child and the choice of the parent regarding the gender and type of coat.

\begin{tabular}{|c|c|c|c|c|}
\hline \multirow[b]{2}{*}{ Parent's Choice } & \multicolumn{3}{|c|}{ Child's Choice } & \multirow[b]{2}{*}{ p-value } \\
\hline & $\begin{array}{l}\text { Male } \\
\text { N (\%) }\end{array}$ & $\begin{array}{c}\text { Female } \\
\text { N (\%) }\end{array}$ & & \\
\hline Preference of the Dentist's Gender & & & & $<0.002^{*}$ \\
\hline Female & $123(30.8)$ & $183(45.8)$ & & \\
\hline Male & $55(13.8)$ & $39(9.8)$ & & \\
\hline Preference of the Type of Coat & & & & 0.113 \\
\hline White & $67(16.8)$ & $38(9.5)$ & $39(9.8)$ & \\
\hline Blue & $6(1.5)$ & $5(1.3)$ & $4(1.0)$ & \\
\hline Colored & $105(26.3)$ & $44(11.0)$ & $92(23.0)$ & \\
\hline
\end{tabular}

*Chi-square test $(\mathrm{p}<0.05)$.

Table 6. Distribution of frequency of children's anxiety according to the Children's Fear Survey Schedule-Dental Subscale (CFSS-DS).

\begin{tabular}{lccccc}
\hline \multicolumn{1}{c}{ Variables } & Not Afraid & A Little Afraid & Fairly Afraid & Quite Afraid & Very Afraid \\
& $\mathrm{N}(\%)$ & $\mathrm{N}(\%)$ & $\mathrm{N}(\%)$ & $\mathrm{N}(\%)$ & $\mathrm{N}(\%)$ \\
\hline Afraid of Dentist & $240(60.0)$ & $48(12.0)$ & $49(12.3)$ & $13(3.3)$ & $50(12.5)$ \\
Afraid of Anesthesia & $140(35.0)$ & $28(7.0)$ & $41(10.3)$ & $12(3.0)$ & $179(44.8)$ \\
Afraid of Choking & $183(45.8)$ & $39(9.8)$ & $52(13.0)$ & $25(6.3)$ & $101(25.3)$ \\
Afraid of People Wearing White Clothes & $332(83.0)$ & $20(5.0)$ & $21(5.3)$ & $6(1.5)$ & $21(5.3)$ \\
\hline
\end{tabular}

Among the children included in the study, 315 (78.8\%) were not anxious, while 85 (21.3\%) were anxious. The children's level of anxiety did not influence the preference for a given gender of the dentist, nor did it influence the preference for the color of the dentist's coat ( $\mathrm{p}=0.966$ and $\mathrm{p}=0.511$, respectively). The procedures dental scaling, restoration, extraction and pulp treatment did not influence the children's level of anxiety ( $\mathrm{p}=0.771 ; \mathrm{p}=0.643 ; \mathrm{p}=0.496$ and $\mathrm{p}=0.747$, respectively). Children with previous experience of prophylaxis and topical application of fluoride more frequently obtained the result of non-anxious ones, and children without such experience obtained the result of greater level of anxiety $(\mathrm{p}<0.001)$. The same pattern was observed for children who answered the option "others" among the types of treatment $(\mathrm{p}<0.008)($ Table 7$)$.

Table 7. Distribution of children according to the level of anxiety and dentist's gender, type of coat and previous dental procedures.

\begin{tabular}{|c|c|c|c|}
\hline \multirow[b]{2}{*}{ Variables } & \multicolumn{2}{|c|}{ Level of Anxiety } & \multirow[b]{2}{*}{ p-value } \\
\hline & $\begin{array}{c}\text { Not Anxious } \\
\text { N (\%) }\end{array}$ & $\begin{array}{l}\text { Anxious } \\
\mathrm{N}(\%)\end{array}$ & \\
\hline All Children & $315(78.8)$ & $85(21.3)$ & \\
\hline \multicolumn{4}{|l|}{ Gender } \\
\hline Prefer Male Dentist & $140(35.0)$ & $38(9.5)$ & 0.966 \\
\hline Prefer Female Dentist & $175(43.8)$ & $47(11.8)$ & \\
\hline \multicolumn{4}{|l|}{ Type of Coat } \\
\hline Prefer White Coat & $114(36.0)$ & $34(8.5)$ & 0.511 \\
\hline Prefer Blue Coat & $65(16.3)$ & $22(5.5)$ & \\
\hline Prefer Colored Coat & $106(26.5)$ & $29(7.2)$ & \\
\hline \multicolumn{4}{|c|}{ Dental Procedures Children Were Previously Submitted To } \\
\hline Prophylaxis or Fluoride Application & & & $<0.001^{*}$ \\
\hline Yes & $247(61.8)$ & $51(12.8)$ & \\
\hline No & $68(17.0)$ & $34(8.5)$ & \\
\hline Dental Scaling & & & 0.771 \\
\hline Yes & $14(3.5)$ & $3(0.8)$ & \\
\hline No & $301(75.3)$ & $82(20.5)$ & \\
\hline Restoration & & & 0.643 \\
\hline Yes & $121(30.3)$ & $35(8.8)$ & \\
\hline
\end{tabular}




$\begin{array}{lcc}\text { No } & 194(48.5) & 50(12.5) \\ \text { Extraction } & & 0.496 \\ \text { Yes } & 74(18.5) & 23(5.8) \\ \text { No } & 241(60.3) & (15.5) \\ \text { Pulp Treatment } & & 3(0.8) \\ \text { Yes } & 9(2.3) & 82(20.5) \\ \text { No } & 306(76.5) & 1(0.3) \\ \text { Other } & 32(8.0) & 84(21.0) \\ \text { Yes } & 283(70.8) & <0.008^{*} \\ \text { No } & & \end{array}$

Having previous experience at the dentist influenced the choice of the dentist's gender. Children who had already consulted preferred more female dentists and children who had never been to an office, preferred male dentists $(\mathrm{p}<0.012)$. The same pattern was not observed in the preference of the dentist's coat, where there was no interference from the previous consultation $(\mathrm{p}=0.371)$ (Table 8).

Table 8. Distribution of children's preference in relation to the dentist's gender and type of coat according to previous experience at the dentist.

\begin{tabular}{|c|c|c|c|}
\hline \multirow[b]{2}{*}{ Variables } & \multicolumn{3}{|c|}{ Previous Experience at the Dentist } \\
\hline & $\begin{array}{c}\text { Yes } \\
\text { N (\%) }\end{array}$ & $\begin{array}{c}\text { No } \\
\text { N (\%) }\end{array}$ & p-value \\
\hline Preference of the Dentist's Gender & & & $<0.012^{*}$ \\
\hline Male & $149(37.3)$ & $29(7.2)^{*}$ & \\
\hline Female & $204(51.0)^{*}$ & $18(4.5)$ & \\
\hline Preference of the Type of Coat & & & 0.371 \\
\hline White & $156(39.0)$ & $22(5.5)$ & \\
\hline Blue & $74(18.5)$ & $13(3.3)$ & \\
\hline Colored & $123(30.7)$ & $12(3.0)$ & \\
\hline
\end{tabular}

\section{Discussion}

This study found that children have specific preferences in relation to gender and the professional coat worn by the dentist, different from their parents and from the popular belief that children prefer dentists wearing colored coats. It was also observed the relationship between level of anxiety and the dental treatment that the child has already undergone, where children with previous experience in the dentist more often obtained the result of non-anxious, and children without such experience obtained the result of greater level of anxiety, thus, the null hypothesis was rejected.

The children in this study preferred female dentists, but there was a tendency for the child to choose the professional with the same gender as theirs, so boys chose more male dentists and girls more female dentists. This finding is similar to that of previous studies [6-8,11,12,18] and different from the findings of Münevveroğlu et al. [10], in which most children preferred to be treated by a female dentist regardless of the child's gender. Thus, it is possible that dentists of the same gender as their pediatric patients have a tendency to have less resistance to assist them [6].

When the children were invited to choose between photos of dentists wearing different types of professional coats, they preferred the formal white coat, with a big difference from the other colors of coats, however there was no difference between the choice of the coat between boys and girls, printed/pediatric coat being the least favored. As observed in previous studies, involving children from different countries and 
cultures $[3,4,6,8,13,14,18]$, this study suggests that children feel more comfortable when they see the dentist with the white coat. Although some studies found different preferences by the children [7,10-12].

Dental history was accessed to identify whether children's anxiety or preference is related to previous experiences. In this research, $88.3 \%$ of the children had already attended the dentist and this fact influenced the option for the gender of the dentist. Children who had already consulted preferred female dentists and children who had never visited an office preferred male dentists. A possible explanation for this difference is the fact that where the research was conducted, as well as throughout Brazil, the female dentists represent about $90 \%$ of the pediatric dentists [19]. Thus, it is plausible that most of the children who have already been consulted, have been consulted by female dentists and in this way the preference can be related to previous experience, especially if it was positive.

An anxiety scale was used to measure the level of anxiety of children facing different dental situations. It was observed that children were more afraid of anesthesia $(44.8 \%)$, similar to the studies by Subramanian and Rajasekaran [7], 76\%, and Münevveroğlu et al. [10], 60\%, but with a lower percentage.

It is interesting to note in this study that children with previous experience of prophylaxis and fluoride application were less anxious than children who did not have this experience. This corroborates the hypothesis raised that suggested that children with previous experience probably had positive experiences, as found in previous studies [8,10]. On the other hand, in the study by Tong et al. [12], children with a higher number of dental appointments tended to have greater anxiety. This shows that the pediatric patients' anxiety, as well as their behavior, are influenced by multiple determinants like parenting style, parental socioeconomic status, oral health behaviours, and dental caries among others [20].

As for the guardian's preference over the dentist's coat, it was observed that while the children preferred the formal white coat, the parents chose the colorful, pediatric coat. This finding is similar to the study by Ellore et al. [18], and differs from the finding in studies by Mistry and Tahmassebi [9] in which parents were significantly more likely to prefer formal attire and children the informal attire. The preference for the professional in white coat suggests an image of professionalism that would increase patient confidence [6]. In addition, children may have become accustomed to the conventional clothing that health professionals, such as pediatricians and family doctors wear [13]. The preference for traditional clothing may also be related to the pre-established image that children have about the figure of the dentist, or their previous experience.

There was a significant concordance between the choice of the dentist's gender by the guardian with the child's preference, similar to the study by Mistry and Tahmassebi [9].

No other study was found addressing the preference of children in relation to the gender and dentist coat conducted with Latin American or Brazilian children [5]. This study showed that children in this Brazilian subpopulation had similar preferences to children from other regions of the world such as Singapore [12], India [3,6,7,18], Turkey [13] and Saudi Arabia [4,8].

The main limitation of this study is the convenience of the sample, which was subject to selection bias, in which a discrepancy was observed between the representation of female parents compared to male. Thus, the staggering of the results, especially related to the parents' preference, must be done with caution.

\section{Conclusion}

The study identified that children have strong preferences in relation to the appearance of their dentists. Children and parents preferred female dentists, but there was a tendency to choose the professional with the same gender as theirs. The results also suggest that children would feel more comfortable with the 
formal white coat, different from the guardian who chose the pediatric coat. The children's level of anxiety did not influence the preference for a given gender of the dentist, nor did it influence the preference for the color of the coat.

\section{Authors' Contributions}

\begin{tabular}{|c|c|c|}
\hline LERV (D) & https://orcid.org/0000-0002-2969-1963 & $\begin{array}{l}\text { Conceptualization, Methodology, Formal Analysis, Investigation, Data Curation, Writing - } \\
\text { Original Draft, Writing - Review and Editing, Visualization and Supervision. }\end{array}$ \\
\hline LAS & https://orcid.org/0000-0003-4240-2879 & $\begin{array}{l}\text { Conceptualization, Methodology, Investigation, Resources, Data Curation, Writing - Original } \\
\text { Draft, Supervision, Project Administration and Funding Acquisition. }\end{array}$ \\
\hline IOG & https://orcid.org/0000-0002-0539-530X & Conceptualization, Methodology, Formal Analysis, Investigation and Writing - Original Draft. \\
\hline ATCN iD & https://orcid.org/0000-0001-8501-5276 & Conceptualization, Methodology, Formal Analysis, Investigation and Writing - Original Draft. \\
\hline AMFA (i) & https://orcid.org/0000-0003-0014-7937 & $\begin{array}{l}\text { Conceptualization, Methodology, Formal Analysis, Data Curation, Writing - Original Draft, } \\
\text { Supervision, Project Administration and Funding Acquisition }\end{array}$ \\
\hline
\end{tabular}

\section{Financial Support}

The authors thank the UNIC/FUNADESP for the academic scholarship of the author Lucilene Abigail dos Santos.

\section{Conflict of Interest}

The authors declare no conflicts of interest.

\section{Data Availability}

The data used to support the findings of this study can be made available upon request to the corresponding author.

\section{References}

[1] Buldur B. Behavior management in pediatric dentistry: an overview and interpretation. Pesqui Bras Odontopediatria Clín Integr 2019; 19(1):e4649. https://doi.org/10.4034/PBOCI.2019.191.ed 1

[2] Buldur B. Angel or devil? Dentists and dental students conceptions of pediatric dental patients through metaphor analysis. J Clin Pediatr Dent 2018; 42(2):119-24. https://doi.org/10.17796/1053-4628-42.2.7

[3] Panda A, Garg I, Bhobe AP. Children's perspective on the dentist's attire. Int J Paediatr Dent 2014; $24(2): 98-103$. https://doi.org/10.1111/ipd.12032

[4] Almutairi MA, Al-Essa NA. Children and parent's preferences of dentists' attire in pediatric dental practice. PODJ 2016; 36(3):417-20.

[5] Kastelic DR, Volpato LE, de Campos Neves AT, Aranha AM, Martins CC. Do children and adolescents prefer pediatric attire over white attire during dental appointments? a meta-analysis of prevalence data. Int $\mathrm{J}$ Clin Pediatr Dent 202 1; 14(1):14-29. https://doi.org/10.5005/jp-journals-10005-1861

[6] Ravikumar D, Gurunathan D, Karthikeyan S, Subbramanian E, Samuel VA. Age and environment determined children's preference towards dentist attire: a cross-sectional study. J Clin Diagn Res 2016; 10(10):ZC16-ZC19. https://doi.org/10.7860/JCDR/2016/22566.8632

[7] Subramanian P, Rajasekaran S. Children's perception of their dentists. Res J Pharm Biol Chem Sci 2016; 7(2):787-91.

[8] Alsarheed M. Children's perception of their dentists. Eur J Dent 2011; 5(2):186-90.

[9] Mistry D, Tahmassebi JF. Children's and parents' attitudes towards dentists' attire. Eur Arch Paediatr Dent 2009; 10(4):237-40. https://doi.org/10.1007/BF03262689

[10] Münevveroğlu AP, Ballı Akgöl B, Erol T. Assessment of the feelings and attitudes of children towards their dentist and their association with oral health. ISRN Dent 2014; 2014:867234. https://doi.org/10.1 155/2014/867234

[11] Asokan A, Kambalimath HV, Patil RU, Maran S, Bharath KP. A survey of the dentist attire and gender preferences in dentally anxious children. J Indian Soc Pedod Prev Dent 2016; 34(1):30-5. https://doi.org/10.4103/0970-4388.175507

[12] Tong HJ, Khong J, Ong C, Ng A, Lin Y, Ng JJ, et al. Children's and parents' attitudes towards dentists' appearance, child dental experience and their relationship with dental anxiety. Eur Arch Paediatr Dent 2014; 15(6):377-84. https://doi.org/10.1007/s40368-014-0126-z

[13] Kuscu OO, Caglar E, Kayabasoglu N, Sandalli N. Short communication: preferences of dentist's attire in a group of Istanbul school children related with dental anxiety. Eur Arch Paediatr Dent 2009; 10(1):38-41. https://doi.org/10.1007/BF03262666

[14] Nirmala SV, Veluru S, Nuvvula S, Chilamakuri S. Preferences of dentist's attire by anxious and nonanxious Indian children. J Dent Child 2015; 82(2):97-101. 
[15] American Society of Anesthesiologists. ASA Physical Status Classification System. 2014. Available from: https://www.asahq.org/Home/For-Members/Clinical-Information/ASA-Physical-Status-Classification-System. [Accessed on August 24, 2020].

[16] Majstorovic M, Veerkamp JS, Skrinjaric I. Reliability and validity of measures used in assessing dental anxiety in 5to 15-year-old Croatian children. Eur J Paediatr Dent 2003; 4(4):197-202.

[17] Gustafsson A, Arnrup K, Broberg AG, Bodin L, Berggren U. Child dental fear as measured with the Dental Subscale of the Children's Fear Survey Schedule: the impact of referral status and type of informant (child versus parent). Community Dent Oral Epidemiol 2010; 38(3):256-66. https://doi.org/10.1111/j.1600-0528.2009.00521.x

[18] Ellore VPK, Mohammed M, Taranath M, Ramagoni NK, Kumar V, Gunjalli G. Children and parent's attitude and preferences of dentist's attire in pediatric dental practice. Int $J$ Clin Pediatr Dent 2015; 8(2):102-7. https://doi.org/10.5005/jp-journals-10005-1293

[19] Brazilian Federal Council of Dentistry. General Number of Specialist Dental Surgeons. 2020. Available from: https://website.cfo.org.br/estatisticas/quantidade-geral-de-cirurgioes-dentistas-especialistas/. [Accessed on August 21, 2020]. [In Portuguese].

[20] Buldur B. Pathways between parental and individual determinants of dental caries and dental visit behaviours among children: Validation of a new conceptual model. Community Dent Oral Epidemiol 2020; 48(4):280-7. https://doi.org/10.1111/cdoe.12530 